\title{
La gestión del buril en el marco de las cadenas operativas del nivel IV.4 (Magdaleniense Superior) de la Cueva de La Pila (Cantabria)
}

\author{
MERCEDES LLORET*
}

\section{RESUMEN ABSTRACT}

Este articulo presenta brevemente los modelos de la dinámica tecnológica observada en uno de los niveles (IV.4) de ocupación Magdaleniense superior de la cueva de La Pila con el objeto de caracterizar el comportamiento de los hombres que habitaron el lugar en el desarrollo de su producción lítica.

\section{PALABRAS CLAVE} La Pila, Magdaleniense superior, tecnología, cadenas operativas.
This article presents the technological models which have been observed in the upper Magdalenian level (IV.4) at La Pila cave in order to show the dinamic behaviour to select their lithic production.

\section{Key Words}

La Pila cave, Upper Magdalenian, technology, reduction sequences.

La Pila es un yacimiento en cueva que está situado cerca de la Playa de Marzán y a casi un kilómetro de la ribera derecha del estuario de San Martín de la Arena de la desembocadura del río Besaya, en el término de Cuchía, en el municipio cántabro de Miengo. Sus coordenadas geográficas son $0^{\circ} 20^{\prime} 08^{\prime \prime} / 43^{\circ} 25^{\prime} 55^{\prime \prime}$. (Fig. 1.)

La cueva fue sometida a diversos sondeos desde los años sesenta pero fue entre los años 1982 y 1985 que Gutiérrez Sáez, C., y Bernaldo de

\footnotetext{
* Colaboradora del Departamento de Prehistoria, UNED. Madrid.
} 


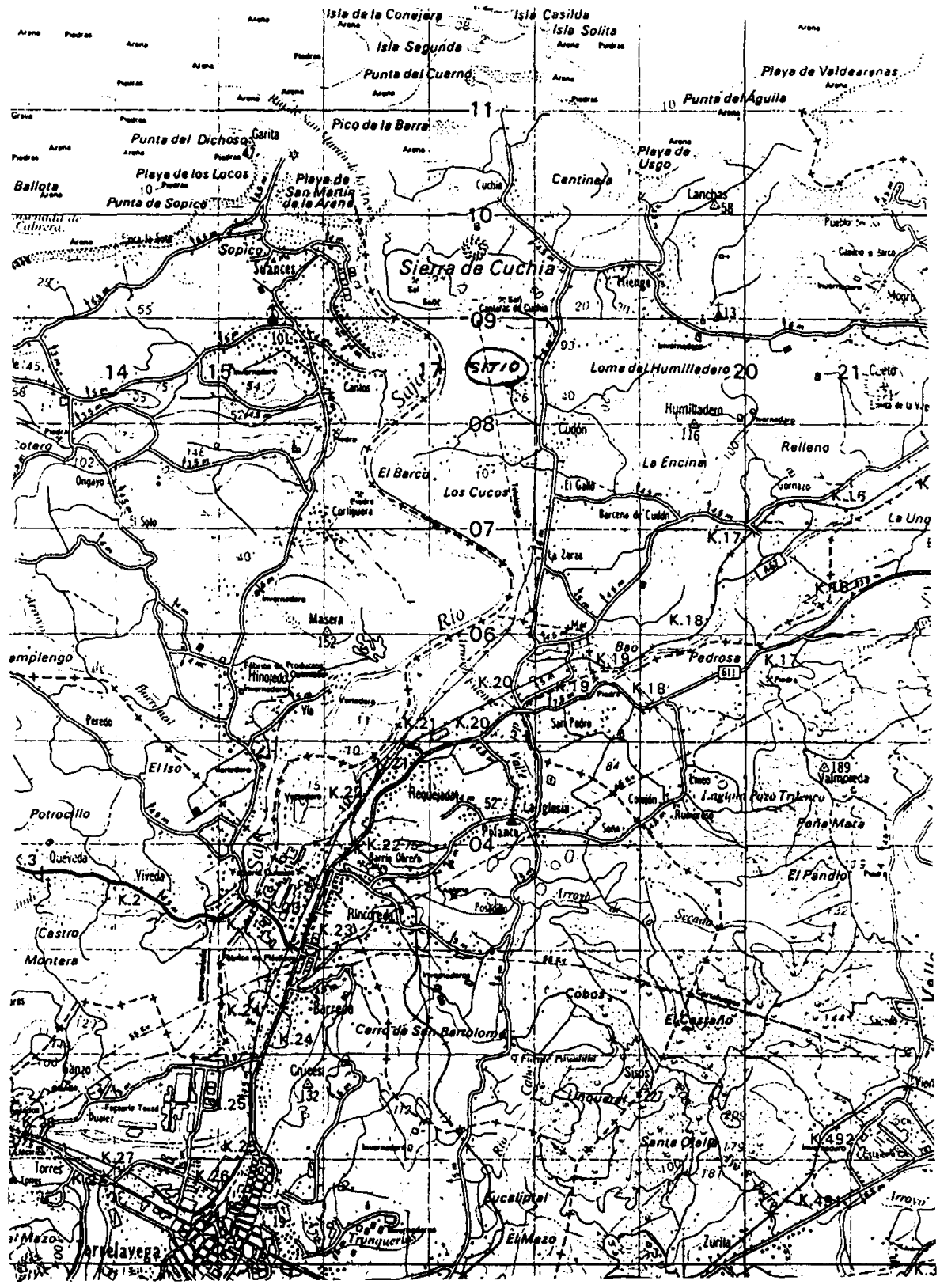

Figura 1. Situación de la cueva de La Pila (Cantabria). 
Quirós, F. efectuaron un programa de excavación que proporcionó la siguiente secuencia estratigráfica y cultural:

- Conjunto de dos niveles revueltos en los que aparecen fragmentos de cerámica, restos líticos y restos de botellas recientes.

- Conjunto con conchero de fauna malacológica de clima frío y materiales azilienses. Está formado por cuatro niveles :

- Nivel III.1, matriz terrosa escasa y de color negro nítido.

- Nivel III.2, matriz más arcillosa y de menor grosor, de color marrón.

- Nivel III.3, matriz terrosa escasa y de color negro.

- Nivel III.4, matriz arcillosa con algunos cantos e industria de aspecto aziliense. La presencia de moluscos se reduce.

- Nivel III.4b, matriz arcillosa muy compacta, sólo se encuentra en la zona más externa de la cueva acuñándose rápidamente hacia el interior. Sobre él se depositan los niveles de conchero.

- Conjunto sin conchero y con materiales magdalenienses. Está formado por cuatro niveles:

- Nivel IV.1, matriz no muy gruesa de color negro. Presencia de cantos. Los restos de moluscos han desaparecido prácticamente.

- Nivel IV.2, matriz arcillosa compacta rojiza con cantos redondeados. Es el nivel de mayor potencia estratigráfica y de mayor riqueza.

Estos dos niveles, IV.1 y IV.2 corresponden a un magdaleniense final.

- Nivel IV.3, matriz de color negro con cantos. Está separado del nivel inferior por lentejones de arcilla compacta.

- Nivel IV.4, matriz de color negro con cantos, similar al nivel superior.

Estos dos niveles, IV.3 y IV.4 corresponden a un magdaleniense superior.

Por último el nivel $V$ de matriz arcillosa, se articula con bloques desprendidos del fondo de la cueva. Los restos líticos de este nivel han sido incorporados al nivel IV.4 después de ser aplicado el método de los remontajes líticos entre ambos niveles proporcionando unos encadenamientos líticos afines a una misma serie lítica que confirmamos como magdaleniense superior (Lloret, 1995). 
La posición estratigráfica de las ocupaciones es muy coherente junto con las dos dataciones obtenidas para los niveles III.3 y IV.2 cedidas amablemente por Bernaldo de Quirós, F., y Gutiérrez, C.

Para la ocupación aziliense del nivel III.3 se obtuvo una fecha de $11.710 \pm 120 \mathrm{BP}$ (GIF 8040).

Para la ocupación magdaleniense del nivel IV.2 tenemos una fecha de $12.160 \pm 130$ BP (8047).

En la ocupación del magdaleniense superior de la cueva de la Pila nos encontramos que los procesos operativos en la gestión de sus materias primas está configurada hacia una producción laminar siendo ésta procesada bajo dos modalidades diferentes, así se observa una producción de láminas y una producción de hojitas siendo ésta última el principal objetivo de los magdalenienses para destinarla a la fabricación de las «hojitas de dorso". Dentro de este marco de esquema productivo se constató a su vez un grupo de útiles fabricados sobre unos soportes que no pertenecían a la fase de pleno desbastado, es decir a los soportes propios del sistema de producción observado. Por este motivo, nuestra preocupación se centra ahora sobre lo que entendemos como una posible cadena operativa secundaria y/o terciaria sujetas a un modelo oportunista tecnológico que no tipológicos como veremos a continuación.

Para un primer acercamiento a este problema diferenciaremos entre lo que entendemos por modelos procesuales y modelos post-procesuales $u$ "oportunistas" como lo llamaremos de aquí en adelante con el fin de ir estableciendo de alguna manera la dinámica tecnológica del proceso operativo de la serie estudiada.

Todo proceso operativo presenta una serie de fases cuya gestión se inicia desde la búsqueda y selección de la materia prima a utilizar, es decir la adquisición de la materia prima y la transformación de ésta mediante unos métodos de desbastado que no son otra cosa que las maneras de hacer manifiestas de una forma de procesamiento mental. Este se refleja en las fases que conocemos como fase de iniciación, fase del propio desbastado y por último las fases de fabricación del útil y abandono de éste así como de los demás soportes, restos de núcleos y productos de acondicionamiento y reparación. Estos últimos son tenidos en cuenta e incluidos como elementos imprescindibles para comprender como veremos en este trabajo una intencionalidad selectiva en el momento de escoger los soportes para un utillaje determinado.

Con el estudio de los modelos de intencionalidad que se vienen realizando en algunas series líticas de la cornisa cantábrica (Cabrera, V.; 
Lloret, M.; Bernaldo de Quirós, F.,1997) se ha podido comprobar que en la fabricación del utensilio podemos encontrarnos con unas cadenas operativas en función del establecimiento de una estructura técnica así como en función de un comportamiento selectivo de tipo oportunista que se enmarcarían bajo los siguientes modelos:

1. partiendo de la cadena operativa principal con el establecimiento de un soporte predeterminado destinado para un determinado útil.

2. tomando de un producto de acondicionamiento de un núcleo, "elemento predeterminante" como soporte para determinado útil. Y es entonces cuando dándose este caso lo denominaremos por nuestra parte «cadena secundaria" y que según venimos observando en otras series líticas como los niveles auriñacienses de la cueva del Castillo (Cabrera Valdés et alii., 1997), y niveles magdalenienses y azilienses de la cueva de la Pila (Lloret,1995), la cadena secundaria se identifica muy bien cuando estudiado el grueso del utillaje lítico puesto en relación a la selección y utilización del soporte así como en la manera de transformar éste observamos que el útil revierte sobre el útil marcador del conjunto del utillaje de la serie analizada.

A mi modo de entender, en ambos casos se opera según un proceso mental ya configurado con la diferencia de que determinados útiles están realizados sobre unos soportes que no corresponden a la fase de producción propiamente dicha aunque si pudieran corresponder a la gestión de una cadena secundaria establecida de antemano por el propio artesano tallador.

3. La cadena terciaria de aprovechamiento parte de una gestión ya hecha. Parte de un producto "predeterminado" o subproducto "predeterminante", no configurando el proceso de obtención del soporte aunque si el útil o la fabricación de éste.

4. El reavivado del útil. Puede ocurrir que un útil agotado o roto se reavive para volver a ser utilizado pudiéndonos encontrar con el resto de un útil roto y/o la presencia del mismo tipo de útil $u$ otro útil diferente en el mismo soporte. Estaríamos entonces ante el aprovechamiento del soporte concatenado a la morfología de éste.

Tanto la cadena terciaria como el reavivado de un útil no configuran el proceso de obtención de un soporte aunque si la fabricación de un útil tanto por extracciones de modificación de la propia morfología del soporte que se producen en algunos casos como por retoque en la fabricación del útil. 
Son por tanto modelos oportunistas tecnológicamente aunque no desde

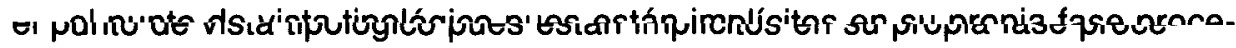
sual de fabricación funcional.

Los modelos procesuales presentan una diferencia con «el oportunismo" y «el reavivado" en tanto que como modelos no procesuales tecnológicamente no ofrecen una intencionalidad en orden a la consecución de un producto predeterminado. Se trata mas bien del aprovechamiento casual de algo ya producido, es decir no presenta gestión productiva alguna sino que sólo toma como algo ya acabado y no pensado "a priori», y es a partir de ahí que se modifica morfológicamente siendo dicha modificación una fase de modalidad tipológica con una estructura técnica-morfológica diferente. En definitiva, el oportunismo como modelo no procesual no es operante ni operativo desde el punto de vista tecnológico sino un aprovechamiento de la consecución de un proceso operativo mientras que la cadena secundaria está inmersa en el propio proceso operativo. Así pues entendemos que en el oportunismo se obvia la fase tecnoprocesual en cuya estructura técnica son imprescindebles tanto lo predeterminante como lo predeterminado.

El modelo oportunista no está proyectado a la consecución de un determinado soporte para un útil concreto sino a la necesidad en un momento dado de un útil por lo que en dicho modelo nos encontramos un comportamiento tecnotipológico caracterizado por una disparidad de útiles variados mientras que en la cadena secundaria el útil está más en consonancia con el útil buscado en la cadena operativa principal y por tanto más acorde con el útil marcador de la serie lítica.

En el conjunto lítico de la serie estudiada del nivel IV.4 de ocupación magdaleniense ("magdaleniense superior») de la cueva de la Pila se pretende determinar si algunos útiles y en concreto «los buriles" han sido fabricados mediante un modelo no procesual lo que indicaría a mi modo de entender la dinámica tecnológica, no sólo como un aprovechamiento de la materia prima sino como una gran capacidad en la manufactura del utillaje mientras que si nos encontramos que pertenecen a una cadena secundaria estaríamos ante un mismo parámetro de orden tipológico lo que indicaría una gestión en una línea más estandarizada.

El proceso operativo gestionado por los hombres magdalenienses del nivel IV.4 comprendía tres cadenas operativas (Lloret, 1995) siendo la producción laminar de hojitas el objetivo principal de los ocupantes de la cueva que destinaron dichos soportes para la fabricación de las «hojitas de dorso". No obstante en la dinámica procesual del esquema productivo 
se advierte una cadena operativa cuya producción aunque también la......minar ha_sidadẹstioada_a_la obtención de láminas medianas con un fin un tanto más diversificado en la consecución del utillaje como veremos en seguida.

\begin{tabular}{|c|c|c|}
\hline \multirow[b]{2}{*}{ PIEZA TECNOLÓGICA } & \multicolumn{2}{|c|}{ MATERIA PRIMA } \\
\hline & Silex & Cuarcita \\
\hline $\begin{array}{l}\text { I FASE } \\
\text { la Descortezado } \\
\text { Bloque bruto } \\
\text { Lasca cortical } \\
\text { Lasca en parte cortical }\end{array}$ & $\begin{array}{r}38 \\
336\end{array}$ & $\begin{array}{c}\text { Percutor } \\
2 \\
218\end{array}$ \\
\hline $\begin{array}{l}\text { Ib Preparación } \\
\text { Lasca no cortical } \\
\text { Lámina cortical } \\
\text { Lámina en parte cortical }\end{array}$ & $\begin{array}{r}577 \\
- \\
43\end{array}$ & $\begin{array}{c}163 \\
- \\
-\end{array}$ \\
\hline $\begin{array}{l}\text { Il FASE } \\
\text { Lámina con cresta } \\
\text { Lámina subcresta } \\
\text { Lámina con cresta segunda } \\
\text { Tableta } \\
\text { Semitableta } \\
\text { Lámina } \\
\text { Hojita } \\
\text { Flanco de núcleo } \\
\text { Núcleo } \\
\text { Fragmento de núcleo } \\
\text { Fragmento de cornisa } \\
\text { Chunk } \\
\text { Fragmento indeterminado }\end{array}$ & $\begin{array}{r}5 \\
11 \\
13 \\
19 \\
24 \\
233 \\
116 \\
33 \\
8 \\
21 \\
8 \\
7 \\
46\end{array}$ & $\begin{array}{l}1 \\
- \\
- \\
- \\
1 \\
6 \\
1 \\
- \\
2 \\
- \\
- \\
-\end{array}$ \\
\hline $\begin{array}{l}\text { III FASE } \\
\text { Golpe de buril }\end{array}$ & 19 & - \\
\hline
\end{tabular}

Las fases de desbastasdo según materias primas del nivel IV.4 de la cueva de la Pila

Por último, no dejaremos de mencionar una tercera cadena operativa de producción lascar que aunque presenta un sistema morfológico diferente de configuración productiva no se aleja de la producción laminar a la hora de seleccionar los soportes según dimensiones para los diferentes grupos de útiles. Este esquema de producción se ha realizado en mayor cuantía sobre el silex tipo «S1" y «S3", aunque también está presente sobre la cuarcita de grano fino tipo "C1.1". 


\section{LOS BURILES DEL NIVEL IV.4}

\section{Los soportes}

Los útiles en silex del nivel IV.4 están realizados sobre un $47,05 \%$ de hojitas; un $22,94 \%$ de láminas; un $27,05 \%$ de lascas y un $2,96 \%$ de resto de piezas de acondicionamiento y reparación de núcleo así como golpes de buril.

\begin{tabular}{|c|c|c|c|c|c|}
\hline ÚTIL & PIEZA TECNOLÓGICA & S1 & \$3 & \$4 & $\mathrm{C}_{1}$ \\
\hline & Fragmento de cornisa & 1 & - & - & - \\
\hline & Fragmento de núcleo & 1 & - & - & - \\
\hline & Lasca & 9 & 7 & 1 & 1 \\
\hline \multirow[t]{5}{*}{ Buril } & Lámina & 9 & 2 & - & - \\
\hline & Semitableta & 1 & - & - & - \\
\hline & Lámina subcresta & 1 & - & - & - \\
\hline & Fragmento de cornisa & - & 1 & - & - \\
\hline & Fragmento de núcleo & 2 & 1 & - & - \\
\hline \multirow[t]{3}{*}{ Raspador } & Tableta & 1 & - & - & - \\
\hline & Lasca & 4 & 5 & - & - \\
\hline & Lámina & - & 1 & - & - \\
\hline Raspador-buril & Lámina & 1 & - & - & - \\
\hline Perforador-raspador & Lasca & 1 & - & - & - \\
\hline \multirow[t]{2}{*}{ Raedera } & Lasca & - & 1 & - & 2 \\
\hline & Tableta & - & 1 & - & - \\
\hline Lasca retocada & Lasca & 3 & 5 & - & 1 \\
\hline Hoja retocada & Lámina & 8 & 2 & 1 & 1 \\
\hline Hojita retocada & Hojita & 3 & - & - & - \\
\hline Dorso rebajado & Lasca & 1 & - & - & - \\
\hline \multirow[t]{2}{*}{ Pieza con truncatura } & Lasca & 1 & - & - & - \\
\hline & Lámina & 1 & - & - & - \\
\hline \multirow[t]{2}{*}{ Hoja de dorso } & Lasca & - & 1 & - & - \\
\hline & Lámina & 1 & 2 & - & - \\
\hline \multirow[t]{2}{*}{ Hojita de dorso } & Hojita & 46 & 10 & - & 1 \\
\hline & Golpe de buril & 3 & - & - & - \\
\hline \multirow{2}{*}{ Hojita de dorso apuntada } & Lámina & 2 & 1 & - & - \\
\hline & Lámina & 1 & - & - & - \\
\hline \multirow[t]{2}{*}{ Hojita de dorso denticulada } & Hojita & 10 & 1 & - & - \\
\hline & Golpe de buril & 2 & - & - & - \\
\hline Hojita de dorso truncada & Hojita & 1 & - & - & - \\
\hline Hoja denticulada & Lámina & 1 & - & - & - \\
\hline Hojita denticulada & Lámina & 1 & - & - & - \\
\hline Hoja con retoque alterno & Lámina & 2 & 1 & - & - \\
\hline Hojita con retoque alterno & Hojita & 1 & - & - & - \\
\hline \multirow[t]{2}{*}{ Hojita con retoque fino } & Hojita & 7 & 1 & - & - \\
\hline & Fragmento de cornisa & 1 & - & - & - \\
\hline Pieza con muesca & Lasca & 1 & 1 & - & - \\
\hline
\end{tabular}

Los útiles del nivel IV.4 de la Pila según soporte tecnológico y materia prima. 
En el proceso de configuración de láminas medianas se observó una gestión tipológica de útiles diversos como se puede apreciar en el cuadro adjunto, y donde los buriles aparecen bien representados en una proporción muy similar a la de los buriles sobre lasca.

Deteniéndonos en el buril como útil que proponemos como elemento caracterizador de la cultura que nos ocupa junto con las hojitas de dorso han sido realizados sobre los siguientes soportes: dieciocho sobre lámina, once sobre lasca, uno sobre fragmento de cornisa, uno sobre fragmento de núcleo, uno sobre semitableta, y uno sobre lámina subcresta de una sola vertiente. También incorporamos al estudio los recortes o golpes de buril por ser éstos un elemento esencial en la fabricación de los buriles y que en el intento de realizar los remontajes líticos hemos podido rescatar algunos golpes de buril que si bien no han remontado con los buriles registrados si se ha podido constatar la transformación de cinco recortes de buril en hojitas de dorso asimilables tipológicamente al grueso del resto de hojitas de dorso, no pudiendo ser definidas como recorte de una truncadura de buril sino que han sido transformadas después de sacados dichos recortes según las observaciones realizados en ellos.

Por el contrario, los útiles en cuarcita son escasos registrándose tan solo seis, cuatro de ellos sobre lasca donde destacamos un buril y dos sobre soporte laminar destacando una hojita de dorso.

\section{ESTUDIO DESCRIPTIVO TECNO-TIPOLÓGICO}

\section{Buril sobre Lasca: 18 piezas}

De los 18 buriles siete están realizados sobre lascas enteras y once sobre lascas rotas. De las lascas enteras destaca un "entame" o lasca de primer orden con talón modificado. Cuatro de los fragmentos de lascas presentan algún resto de corteza en su cara superior.

Se trata de buriles diedros pequeños, sólo dos sobrepasan $4 \mathrm{~cm}$. de longitud siendo uno de ellos de cuarcita. El resto de los buriles no sobrepasan de $2 \mathrm{~cm}$. de longitud. Sin embargo el espesor varía de $4 \mathrm{~mm}$ a $12 \mathrm{~mm}$.

Se ha podido distinguir el tipo de talón en los siguientes piezas: tres soportes con talón liso $(4.5 \mathrm{~mm}, 5 \mathrm{~mm}$ y $6 \mathrm{~mm})$ y un soporte con talón puntiforme $(1.5 \mathrm{~mm})$. En cuatro de los soportes aparece resto de preparación en la zona proximal de la cara superior.

La lectura realizada de los negativos dejados por levantamientos anteriores nos proporciona extracciones de tipo lascar en su cara superior en diez de los soportes. 
En cuanto a la materia prima seleccionada para la fabricación del buril, nueve son de silex de buena calidad, ocho de silex de calidad mediocre y uno de cuarcita de calidad mediocre.

Los soportes provienen de la primera fase del proceso operativo de talla; cinco de las piezas de la etapa de descortezado y el resto de la etapa de preparación del núcleo.

\section{Buril sobre fragmento de cornisa: 1 pieza}

Se trata de un buril múltiple sobre truncatura.

Presenta resto de corteza en zona proximal hacia el lateral derecho de la cara superior. Fabrican el útil en la cara inferior, asimismo podemos observar como la truncatura va de la cara superior hacia la inferior. El talón no se identifica. Su tamaño: $2,2 \mathrm{~cm}$. de longitud, $1,9 \mathrm{~cm}$. de anchura y 8,5 $\mathrm{mm}$. de espesor.

En cuanto a la materia prima seleccionada, el buril se ha realizado sobre un fragmento de cornisa de núcleo de base lasca de silex de buena calidad.

Buril sobre fragmento de núcleo: 1 pieza

Realizado sobre un fragmento de núcleo de silex de buena calidad. Su tamaño no sobrepasa los $2,5 \mathrm{~cm}$. de longitud. La pieza proviene de un núcleo de hojitas sacada a través de una lasca que sirve de soporte para la fabricación del buril.

\section{Buril sobre lámina: 11 piezas}

De los once buriles diedros cinco están realizados sobre lámina entera y seis sobre lámina rota. La fractura se encuentra en la zona proximal en cinco de ellas y en una en la zona lateral izquierdo. El talón de los soportes enteros: en dos se trata de talones lisos de $1 \mathrm{~mm}$., y $2 \mathrm{~mm}$. Y en los otros tres aparece modificado. En un soporte se aprecia preparación.

El tamaño de los buriles en los soportes enteros: sólo uno alcanza los $6 \mathrm{~cm}$., y otro los $5 \mathrm{~cm}$. de longitud, el resto no sobrepasa los $3 \mathrm{~cm}$., sin embargo el espesor es más bien fuerte. En los soportes rotos ninguno sobrepasa los $3 \mathrm{~cm}$. de longitud y el espesor es mediano. 
El buril se ha confeccionado en la zona distal lateral izquierdo, salvo en

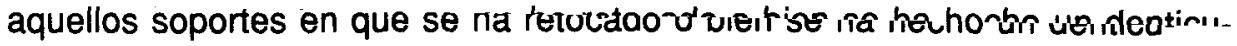
lado observamos que aparece en el lateral derecho. Sólo en uno aparece el retoque denticulado en ambos laterales pero persiste el buril en la zona distal lateral izquierdo.

El índice de regularidad ha podido ser apreciado sólo en tres de las láminas enteras: una lámina de regularidad mediana y dos con índice mediocre, es decir tanto los bordes del soporte como las nervaduras de la cara superior son relativamente rectilíneos y regulares.

En ocho aparecen negativos de extracciones anteriores en su cara superior siendo en cinco de éstas extracciones de tipo laminar.

Nueve de los buriles están fabricados sobre láminas de silex de buena calidad y dos sobre láminas de silex de calidad mediocre.

Los soportes mencionados corresponden a la fase de pleno desbastado laminar.

\section{Golpes de buril: 19 piezas}

Se han registrado diecinueve golpes de buril en silex siendo doce de ellos del tipo "S1" y siete del tipo "S3". Es interesante mencionar que cinco de los golpes de buril del tipo "S1" han sido utilizados como soporte para fabricar tres hojitas de dorso y dos hojitas de dorso denticulada. Los soportes provienen de la propia fase de realización del buril.

Estas piezas después de transformadas en «hojitas de dorso» miden de $1,1 \mathrm{~mm}$. a $2,8 \mathrm{~mm}$. de largo, y de $2 \mathrm{~mm}$ a $4 \mathrm{~mm}$ de ancho presentando una coherencia en sus dimensiones respecto al resto del grupo de las hojitas de dorso de este nivel IV.4 así como un mismo parámetro en cuanto a la selección de la materia prima y el tipo de hojita de dorso realizada (Lloret, 1995:20).

La serie de buriles descritos se completa con tres piezas que no podemos dejar de mencionar. Se trata de un raspador - buril sobre lámina de silex tipo «S1" con un resto muy fino de corteza en la zona izquierda de la cara superior, es una pieza pequeña de $3,9 \mathrm{~cm}$. y de espesor mediano que presenta un indice de regularidad mediano. Las otras dos piezas han sido encontradas en los restos de talla al realizar los remontajes líticos, son interesantes por lo que a su soporte se refiere pues se trata de un buril sobre lámina subcresta, pieza característica de un desbastado laminar, y un buril sobre una semitableta de núcleo. 
La lámina subcresta de una solo vertiente (A2) aparece fracturada siendo reconstruida a través del enlace lítico de su parte proximal y mesial. La parte mesial de la arista o subcresta ha sido tomada como soporte para realizar un buril diedro .

La semitableta de núcleo (TS) con preparación en su cornisa no sobrepasa los $3 \mathrm{~cm}$. de longitud. El buril está realizado sobre el plano de percusión de la semitableta así como en la cara inferior apareciendo asimismo un retoque marginal en la zona distal.

En definitiva, los buriles del nivel IV.4 de La Pila han sido fabricados mayormente en silex de buena calidad.

De los soportes elegidos para realizar los buriles destacan las lascas y las láminas aunque los soportes lascares tienden a dominar. Se trata de piezas de pequeñas dimensiones a excepción de dos buriles sobre lámina que alcanzan los 5 y $6 \mathrm{~cm}$. de longitud.

Ahora bien, los magdalenienses de la cueva de La Pila utilizan cualquier soporte del proceso operativo de la materia prima principalmente el silex para realizar este tipo de útil, así los soportes provienen casi en la misma proporción de la fase de descortezado y de preparación del núcleo que de la fase de pleno desbastado. (Fig. 2).

\section{cadena operativa de "láminas medianas" \\ (soportes destinados a un utillaje diverso)}

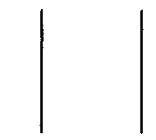

CADENA OPERATIVA PRINCIPAL DE "HOJITAS"

(soportes destinados a la fabricación de "hojitas de dorso")

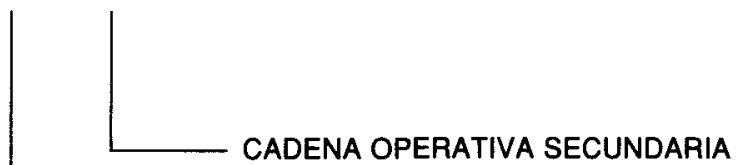

(el golpe de buril es destinado a la fabricación

de "hojitas de dorso")

CADENA TERCIARIA DE APROVECHAMIENTO

(soportes que provienen de productos de acondicionamiento como lámina subcresta, semitableta, son destinados a un utillaje diverso: buril, lámina retocada) 

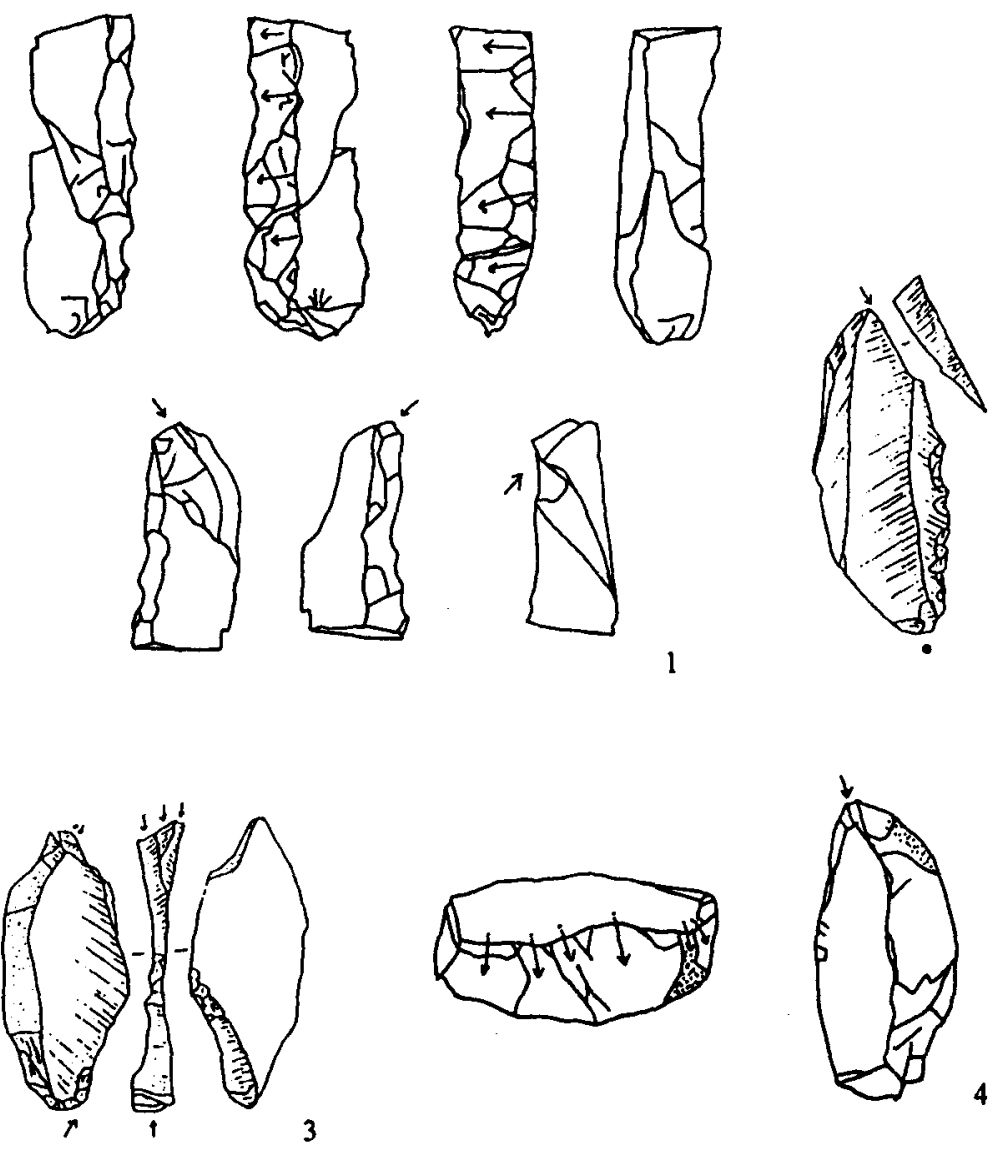

3
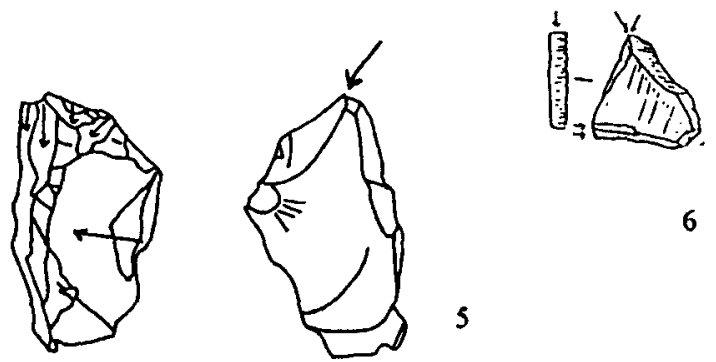

6

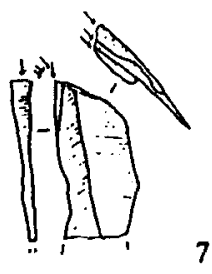

5

Figura 2. Buriles del nivel IV.4 de La Pila. 2-3-4-5 (Dibujo Lagüera). 
Por tanto no podemos decir que la primera intención de los magdalenienses fuera la producción de un soporte predeterminado para la fabrica-

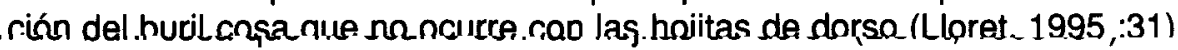
que como hemos comprobado destina la mayor parte de su producción a la fabricación de éstas incluso a través de una segunda cadena operativa.

La configuración laminar presenta cuatro cadenas operativas que establecemos jerárquicamente según un parámetro de intencionalidad productiva. Dos cadenas operativas de producción "per se" siendo una de ellas la cadena operativa principal cuya producción ha sido destinada a la fabricación de hojitas de dorso, útil marcador de la serie lítica estudiada; una segunda cadena operativa gestionada de tal manera que aunque encabece la producción laminar obteniendo láminas de tamaño mediano queda relegada a una segunda intencionalidad tipológica puesto que sus productos han sido destinados a un utillaje diverso (lámina retocada, pieza con muesca, pieza con truncatura, hoja de dorso, siendo el buril el más representativo. Una cadena operativa secundaria caracterizada por la utilización como soporte «el golpe de buril» para fabricar el tipo de útil marcador del conjunto lítico de la cadena operativa principal. Por último, una cadena terciaria de aprovechamiento que aún seleccionando los mismos productos que la anterior gestión, los destina a la fabricación de un utillaje variado donde volvemos a encontrar representado al buril.

Finalmente podemos concluir que en el nivel IV.4 de La Pila se han desarrollado dos modelos de operatividad en la consecución de sus útiles ; un modelo de intencionalidad de producción de soportes laminares en la cadena principal de hojitas asi como en el proceso de láminas medianas y en la cadena secundaria cuya gestión ha sido estandarizada tanto tecnológica como tipológicamente mientras que la cadena terciaria de aprovechamiento se presenta en este nivel como un modelo oportunista sin una estandarización tecnológica que caracterice una intención tipológica.

En cualquier caso este proceso será puesto en relación con aquellos que se vienen observando en los niveles azilienses del mismo yacimiento con el objetivo de comprobar si se siguen los mismos modelos procesuales de estandarización o por el contrario se gestionan otros a causa de intencionalidades diferentes.

\section{BIBLIOGRAFIA}

ARRIzABalaGa, A. (1991): Interrelación entre buriles y recortes de buril. Implicaciones arqueologicas. En Tecnología y Cadenas Operativas Líticas. U.A.B. 15-18, enero, 1991. Treballs d'Arqueología, I, 1991, pp. 263-270. 
AuBry, Th., et alii (1997): Production d'armatures microlithiques pendant le Paléolithique supérieur et le Mésolithique au Portugal. Il Congreso de Arqueología Peninsular. Paleolítico y Epipaleolítico. Tomo I. Zamora, del 24 al 27 de Septiembre de 1996. Ed. Fundación Rei Afonso Henriques. Pp. 259-272.

BERnAldo de Quirós, F. (1980): Notas sobre la economía del Paleolítico Superior. En Monografía del Centro de Investigación y Museo de Altamira, n.e 1. Santander, 44 p.

Bernaldo de Quirós, F. (1982): Los inicios del Paleolítico Superior Cantábrico. En Monografía del Centro de Investigación y Museo de Altamira, n. ${ }^{2}$. Madrid, 347 p.

Bernaldo de QuiRós, F., CaBRera VAldés V. (1991): Bilan de recherches paleolithiques dans la province de Cantabria. Espagne. En Le Paleolithique Superieur Europeen, Bilan Quinquenal, ERAUL 52.

Cabrera Valdés, V. (1984): El yacimiento de la cueva de "El Castillo» (Puente Viesgo, Santander), Biblioteca Praehistorica Hispanica XXII. Madrid, 485 p., fig. (Tesis de Doctorado).

Cabrera Valdés, V., Bernaldo de Quirós, F. (1990): Donnes sur la transition entre le Paleolithique Moyen et le Superieur a la Region Cantabrique; Revision critique. En Paleolithique Moyen Recent et Paleolithique Superieur Ancien en Europe, Memoires du Musée de Prehistoire d'ille de France n. ${ }^{3}$ 3, pp. 185-188.

Cabrera V., Lloret, M., Bernaldo de Quirós, F. (1997): El Auriñaciense Arcaico de la Cueva del Castillo. En II Congreso de Arqueología Peninsular de Zamora (24 al 27 de Septiembre de 1996), pp. 133-140.

CÉLÉRIER, G. (1993): L'abri sous roche de pont d'Ambon à Bourdeille (Dordogne). Gallia Prèhistoire. Fouilles et monuments archéologiques en France métropolitaine. Tome 35 , CNRS éditions. París.

Fernandez Eraso, J. (1982): Propuesta para un estudio analítico de los golpes de buril: el caso del Magdaleniense final de Santimamiñe. ZEPHYRUS XXXIV-XXXV: 47-63.

GonzÁlez SaInz, C. (1989): El Magdaleniense Superior-Final de la región cantábrica. Santander. Ediciones Tantin. Universidad de Cantabria. 317 p., fig. (Tesis de Doctorado).

Ibáñez Estévez, J.J., González UrquiJo, J. E. (1994): La fabricación del utillaje lítico en Laminak II. KOBIE (Serie Paleoantropología) Bilbao. Ed. Diputación Foral de Bizkaia. N. ${ }^{?}$ XXI. 86-110.

KARLIN, C. (1991): Analyse d'un processus technique: le debitage laminaire des magdaleniens de Pincevent (Seine et Marne). Tecnología y Cadenas Operativas Líticas. U.A.B. 15-18 Enero 1991. Treballs d'Arqueología, I, 1991, pp. 125-161.

Lagüera Garcia, M. A. (1991): La tipología del utillaje lítico de La Pila (Cuchía,Mogro, Cantabria). En Espacio, Tiempo y Forma, Serie I, Prehistoria y Arqueología, tomo 4, pp. 37-92, fig. Revista de la Facultad de Geografía e Historia de la U.N.E.D.

Lloret, M. (1995): Análisis tecnológico de los núcleos de la cueva de La Pila (Magdaleniense Superior: Nivel $V$ y IV.4). En Espacio, Tiempo y Forma, Serie I, Prehistoria y Arqueología, tomo 8, pp. 11-32. Revista de la Facultad de Geografia e Historia de la U.N.E.D.

LuCAS, G. (1997): Les lamelles Dufour du Flageolet I (Bézenac, Dordogne) dans le contexte Aurignacien. Paleo, n. ${ }^{9}$ 9. Pp. 191-219.

Mapa Geológico-Minero de Cantabria, Escala 1:100.000. Instituto Tecnológico Geominero de España. Madrid 1990. 133 p. 4 mapas.

Mapa «Hoja n. ${ }^{\circ} 34$ - Torrelavega». Escala 1:50.000. Servicio Geográfico del Ejército.

Pelegrin, J. (1986): Analyse lithique: une méthode appliquée à l'étude de deux séries du Périgordien ancien - Roc de Combe couche 8 - La Cốte niveau III. París: Université de París X.IV 584 p., fig. (Tesis de Doctorado).

PIgeot, N. (1987): Magdalèniens D'Étiolles. Économie de débitage et organisation sociale (L'unité d'habitation U5). En XXVe supplément à GALLIA PRÉHISTOIRE. París 157 p. fig. 
Rigaud, J. Ph. (1982): Le Paléolithique en Périgord : les données du sud-ouest sarladais et leurs implications. Bordeaux: Université de Bordeaux I.Thèse Sci.: Bordeaux I: 1982; $737 \mathrm{p}$.

TURo, A. (1992): Le Palélithique inferieur et moyen entre les valles de la Dordogne et du Lot. Bordeaux: Université de Bordeaux I. 782 p. fig. (Tesis de Doctorado).

VV.AA. (1995): El final del Paleolítico Cantábrico. Universidad de Cantabria. 363 p. 